\title{
FREQUENCY AND DETERMINANTS OF POSTPARTUM DEPRESSION.
}

1. MBBS, M.Phil

Assistant Professor Community Medicine

Independent Medical College, Faisalabad.

2. MBBS, DMCH, DGO, FCPS HOD Community Medicine Independent Medical College, Faisalabad

3. MBBS, MD, FCPS

Assistant Professor, Psychiatry department

HBS Medical College, Islamabad.

4. MBBS, MPH, MCPS

Associate Professor Community

Medicine

Independent Medical College,

Faisalabad.

5. MBBS, MPH

Assistant Professor

Department of Community Medicine Independent Medical College,

Faisalabad.

6. MBBS, FCPS

Consultant Gynaecologist

Correspondence Address:

Dr. Muhammad Umar Ghafoor

Department of Community Medicine

IMC, Faisalabad.

omarghafoor@live.com

Article received on:

27/08/2019

Accepted for publication:

25/10/2019

\section{INTRODUCTION}

Pregnancy and childbirth are a time of significant physical and emotional stress for females. A transient period of low mood and emotional instability is experienced by many new mothers, but $10-15 \%$ of females experience more severe psychological disturbances. These include constant low mood, feelings of worthlessness and hopelessness, sleep and appetite disturbances and an inability to take care of the newborn. ${ }^{1}$ This psychiatric condition, known as postpartum depression (PPD) leads to marked impairment in functioning and mother-child bonding. ${ }^{2}$ Studies from western countries quote figures of postpartum depression as 100-150/1000 live births but there is emerging evidence that PPD is more common in low and middle income countries. ${ }^{2,3}$ and the child. Aftab Nazir ${ }^{5}$, Faiza Irshad ${ }^{6}$

STRACT... Objectives: This study was designed to evaluate the frequency of postpartum a tertiary care hospital in Faisalabad and identify the factors Community Medicine at Independent University Hospital, Faisalabad. Period: Over a period of three months from February 2018 to May 2018. Material \& Methods: Included 213 subjects

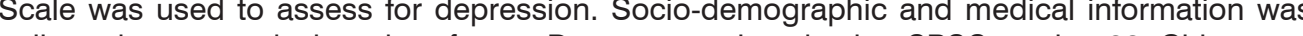
collected on a pre-designed proforma. Data was analyzed using SPSS version 23. Chi square housewives $(77.78 \%$ ) living with extended families $(68.06 \%)$. The difference in the number depressed women among extended and nuclear families was found to be statistically significant ( $\mathrm{p}$-value of 0.004 ). The study also showed that women suffering from postpartum depression were less likely to breastfeed their babies ( $p$-value 0.046). Conclusion: Postpartum depression was identified in more than one thirds of the females included in this study. This high number early intervention can prevent the adverse consequences this disorder carries for the mother

Key words: Postpartum Depression.

Article Citation: Ghafoor MU, Usmani RA, Choudhary ZI, Ahamd S, Nazir A, Irshad F. Frequency and determinants of postpartum depression. Professional Med J 2020; 27(5):1017-1021. DOI: 10.29309/TPMJ/2020.27.05.4081

Postpartum depression presents significant problems for both the mother and the child. Studies suggest that postpartum depression leads to a greater chance of severe psychiatric disorders in females such as psychosis while increasing the risk of suicide and infanticide. ${ }^{4}$ On the other hand, children of mothers with postpartum depression have greater cognitive, behavioral and interpersonal problems compared with the children of non-depressed mothers. ${ }^{5} \mathrm{~A}$ meta-analysis in developing countries showed that the children of mothers with postpartum depression are also at greater risk of being underweight and stunted. ${ }^{6}$

Many biological, psychological and social factors have been implicated as risk factors for postpartum depression ${ }^{7}$ however these studies 
have been predominantly conducted in western societies with their starkly different social and cultural landscapes. There remains a shortage of data from Pakistan which may help to identify the risk factors for postnatal depression in our settings and lead to early intervention and treatment.

The objective of this study was to determine the frequency of postpartum depression among new mothers presenting to the outpatient clinic of a tertiary care hospital and to highlight the associated socio-demographic, obstetric and psychological factors for postnatal depression.

\section{MATERIAL \& METHODS}

This descriptive cross-sectional study was conducted at the community medicine department of Independent University Hospital, Faisalabad from February 2018 to May 2018.

Patients presenting to the OB/GYN outpatient department of the Independent University Hospital who had given birth in the last six months were approached for the study.

Non- probability purposive sampling was used to recruit 213 subjects to the study. The sample size was calculated by Raosoft sample size calculator with $95 \%$ confidence level and $5 \%$ margin of error.

Permission was obtained from administration of Independent University Hospital. The patients were informed about the aims and structure of the study. Written informed consent was taken from all patients willing to participate in the project. The socio-demographic, obstetric and newborn variables were collected on a custom designed questionnaire administered by the interviewer. A pre-validated, Punjabi translation of Edinburgh Postnatal Depression Scale (EPDS) was used to diagnose postpartum depression. A score of 10 or higher on the EPDS was considered significant.

Data was analyzed using the software, Statistical Package for Social Sciences (SPSS), version 23. Descriptive statistics such as mean, standard deviation, frequency and percentage were applied to the socio-demographic, medical and obstetric variables. Chi-square test was applied to ascertain association with a p-value $<0.05$ considered to be significant.

\section{RESULTS}

Out of the total 213 participants, 33.8\% $(n=72)$ were found to be suffering from postpartum depression based on the EPDS score (Figure-1). The mean age of the sample was 28.03 years with a standard deviation of 3.96 and an age range of $19-39$ years. A significant majority (86\%) of the participants were uneducated $(n=185)$ and $75 \%$ $(n=160)$ were housewives.

Frequency of postpartum depression

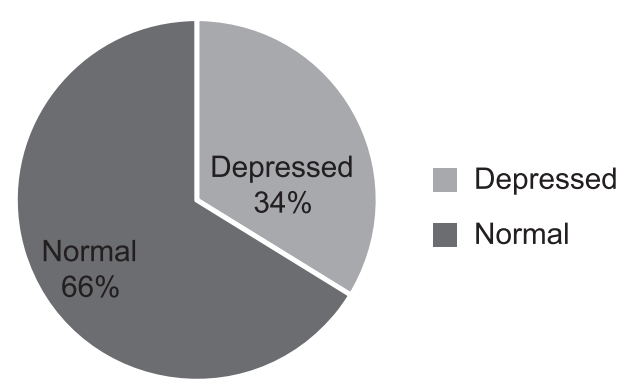

Figure-1. Pie chart showing prevalence of depression in the sample based on EPDS score

Out of the total $213,55 \% \quad(n=118)$ of the participants had delivered through normal vaginal route while $13 \%(n=28)$ of the total babies had been born with congenital defects. Household income of $76 \%(n=166)$ of the participants was less than Rs.50, 000/- per month. The gender of the babies was evenly divided with 100 females and 113 males. $53.9 \%(n=115)$ of the mothers included in the study lived with extended families. Another finding was that the depressed mothers were not breastfeeding their newborns as much as the non-depressed mothers ( $p$-value 0.046) (Figure-2).

The depressed and non-depressed subjects were compared on study variables and Table-I and Table-II summarize the results. 


\begin{tabular}{|c|c|c|c|c|}
\hline Subjects & $\begin{array}{l}\text { Level of } \\
\text { Education }\end{array}$ & Occupation & Family Structure & Monthly Income \\
\hline Depressed & $\begin{array}{c}\text { Educated: } \\
11(15.27 \%) \\
\text { Uneducated: } \\
61(84.72 \%)\end{array}$ & $\begin{array}{c}\text { Housewife: } \\
56(77.77 \%) \\
\text { Working: } \\
16(22.23 \%)\end{array}$ & $\begin{array}{c}\text { Nuclear: } \\
23(31.94 \%) \\
\text { Extended: } \\
49(68.06 \%)\end{array}$ & $\begin{array}{c}<50,000: \\
59(81.94 \%) \\
>50,000: \\
13(18.06 \%)\end{array}$ \\
\hline Non-depressed & $p$-value $=0.525$ & $p$-value $=0.616$ & $p$-value $=0.004$ & $p$-value $=0.383$ \\
\hline
\end{tabular}

Table-I. Comparison of socio-demographic variables among depressed and non-depressed

\begin{tabular}{|c|c|c|c|c|}
\hline Subjects & Mode of Delivery & Gestation Period & Gender of Child & Birth Defects \\
\hline \multirow[t]{2}{*}{ Non-depressed } & $\begin{array}{c}\text { NVD: } \\
82 \text { (58.15\%) } \\
\text { C-section: } \\
59(41.85 \%)\end{array}$ & $\begin{array}{c}\text { Term: } 27(19.14 \%) \\
\text { Pre-term: } 114 \\
(80.86 \%)\end{array}$ & $\begin{array}{c}\text { Male: } \\
69(48.93 \%) \\
\text { Female: } \\
72(51.07 \%)\end{array}$ & $\begin{array}{c}\text { Present: } \\
17 \text { (12.05\%) } \\
\text { None: } \\
124(87.95 \%)\end{array}$ \\
\hline & P-value $=0.308$ & $p$-value $=1.00$ & $p$-value $=0.111$ & $p$-value $=0.525$ \\
\hline
\end{tabular}

Breast feeding and postpartum depression

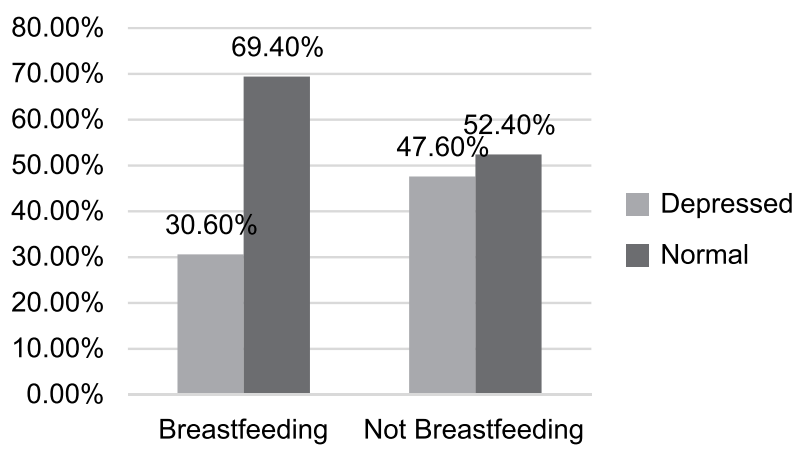

Figure-2. Bar chart showing comparison of the frequencies of breast feeding in the depressed and non-depressed patients. ( $p$-value: 0.046 )

\section{DISCUSSION}

The study looked at the prevalence of postpartum depression in females and tried to identify associated factors which may predispose or perpetuate the disorder. Out of the total 213 participants, $33.8 \%(n=72)$ were found to be suffering from postpartum depression. Studies conducted by Muneer et al in Rawalpindi and Afridi et al in Peshawar showed similar prevalence of postpartum depression. ${ }^{8,9}$ This is in contrast to the studies done in the developed countries where this number is much smaller. ${ }^{10,11}$ This may be attributed to poor antenatal care services, lack of psychological interventions, socioeconomic adversity and worsening geopolitical situation of our country. ${ }^{12}$ A preponderance of the depressed patients was seen to be uneducated housewives with a monthly household income of less than Rs.50, 000. Majority of the depressed women lived in extended families (Table-I) and the difference in the frequency of the two groups was found to be statistically significant. The literature on this issue is divided; one study from USA showed that women living in extended families benefited from greater social support ${ }^{13}$, while studies conducted in our region propose that living with in-laws served may be more stressful, predisposing patients to psychological problems after delivery. ${ }^{14} \mathrm{~A}$ comparison of the obstetric and medical variables of the depressed and nondepressed patients of the sample is given in TableII. Although numerical differences between the two groups are evident, we were unable to ascertain any statistically significant association between mode of delivery, term of gestation and gender of 
child to postpartum depression although previous literature does show this association. ${ }^{15,16}$ Figure-2 shows the bar chart comparing depressed and non-depressed females on breastfeeding. The study showed that females who were depressed were less likely to breast feed their babies. Other studies have also reported early breastfeeding cessation in mothers who are depressed. It has also been hypothesized that breastfeeding may help to reduce postpartum depression in susceptible females. ${ }^{17,18}$

One of the limitations of hospital-based studies such as this one is that it may not be representative of the general population. Additionally, certain variables like years of marriage, previous off springs and quality of marital relationship were not investigated.

\section{CONCLUSION}

A high number of females were found to be suffering from postpartum depression in our study. Postpartum depression needs attention in terms of screening, early intervention and increased psychological support for new mothers.

\section{Copyright@ 25 Oct, 2019.}

\section{REFERENCES}

1. Di Florio A, Smith S, Jones I. Postpartum psychosis. The Obstetrician \& Gynecologist. 2013; 15(3):145-50.

2. Klainin P, Arthur DG. Postpartum depression in Asian cultures: A literature review. Int J Nurs Stud. 2009; 46:1355-73. [PubMed: 19327773].

3. Shrestha N, Hazrah P, Sagar R. Incidence and prevalence of postpartum depression in a rural community of India. J Chitwan Med Coll. 2015; 5(2):11-9.13149.

4. Field T. Postpartum depression effects on early interactions, parenting, and safety practices: A review. Infant Behav Dev. 2010 Feb; 33(1):1-6. PMID: 19962196.

5. Paulden M, Palmer S, Hewitt C, Gilbody S. Screening for postnatal depression in primary care: Cost effective analysis. BMJ 2009; 339: b5203.

6. Norhayati MN, Hazlina NH, Asrenee AR, Emilin WM. Magnitude and risk factors for postpartum symptoms: A literature review. J Affect Disord. 2015; 175:34-52. [PubMed: 25590764].
7. Spinelli MG. Maternal infanticide associated with mental illness: Prevention and the promise of savedlives. Am J Psychiatry. 2004; 161:1548-57. [PubMed: 15337641].

8. Munir A, Minhas FA, Nizami AT, Mujeeb F, Usmani AT. Frequency and associated factors for postnatal depression. J Coll Physicians Surg Pak 2009; 19(4):23639. Symptoms during pregnancy: A systematic review. Am J Obstet Gynecol. 2010; 202:5-14. [PubMed: 20096252]

9. Gaillard A, Le Strat Y, Mandelbrot L, Keïta H, Dubertret C. Predictors of postpartum depression: Prospective study of 264 women followed during pregnancy and postpartum. Psychiatry Res. 2014;215:341-6. [PubMed: 24370337]

10. Figueiredo $B$, Canário $C$, Field $T$. Breastfeeding is negatively affected by prenatal depression and reduces postpartum depression. Psychol Med. 2014; 44:927-36. [PubMed: 23822932]

11. Hamdan A, Tamim H. Psychosocial risk and protective factors for postpartum depression in the United Arab Emirates. Arch Womens Ment Health. 2011; 14:125-33. [PubMed: 21063891]

12. Syed $M$, Angela $B$, lqbal A, Gul N, Nazeem $M$. Prevalence of antenatal depression: Comparison between Pakistani and Canadian women. J Pak Med Assoc Mar 2011; 61(3):242-6.

13. Staehelin K, Kurth E, Schindler C, Schmid M, Zemp SE. Predictors of early postpartum mental distress in mothers with midwifery home care-results from a nested casecontrol study. Swiss Med Wkly. 2013; 143:w13862.

14. Ghazala S, Zahra S. Prospective study on prevalence and risk factors of post natal depression in Rawalpindi/Islamabad, Pakistan. Rawal Med J Jan Mar 2016; 41(1):64-7.

15. Polic B, Bubic A, Mestrovic J, Markic J, Kovacevic T, Juric M, Tesija RA, SusnjarH, Kolcic I. Late preterm birth is a strong predictor of maternal stress later in life: Retrospective cohort study in school-aged children. J Paediatr Child Health. 2016; 52:608-13.

16. Houston KA, Kaimal AJ, Nakagawa S, Gregorich SE, Yee LM, Kuppermann M. Mode of delivery and postpartum depression: The role of patient preferences. Am J Obstet Gynecol. 2015; 212:229.e1-7. [PubMed: 25218957] 
17. Reifsnider E, Flowers J, Todd M, Bever Babendure J, Moramarco $\mathrm{M}$. The relationship among breastfeeding, postpartum depression, and postpartum weight in Mexican American Women. J Obstet Gynecol Neonatal Nurs. 2016 Nov - Dec; 45(6):760-771. Epub 2016 Sep 13.
18. Figueiredo $B$, Canário $C$, Field $T$. Breastfeeding is negatively affected by prenatal depression and reduces postpartum depression. Psychol Med. 2014 Apr; 44(5):927-36. Epub 2013 Jul 3. PMID: 23822932.

\begin{tabular}{|c|c|c|c|}
\hline \multicolumn{4}{|c|}{ AUTHORSHIP AND CONTRIBUTION DECLARATION } \\
\hline Sr. \# & Author(s) Full Name & Contribution to the paper & Author(s) Signature \\
\hline 1 & M. Umar Ghafoor & $\begin{array}{l}\text { Materials \& Methods, Results, } \\
\text { Analysis. }\end{array}$ & \\
\hline 2 & Rabia Arshed Usmani & $\begin{array}{l}\text { Study design, Questionnaire } \\
\text { development. }\end{array}$ & Ration \\
\hline 3 & Zaidan Idrees Ch. & $\begin{array}{l}\text { Introduction, literature review, } \\
\text { discussion, references. }\end{array}$ & \\
\hline 4 & Shahbaz Ahmad & Data collection, Proof reading. & \\
\hline 5 & Aftab Nazir & Data collection, Proof reading. & Fair \\
\hline 6 & Faiza Irshad & Data collection, Proof reading. & \\
\hline
\end{tabular}

